RESEARCH ARTICLE

\title{
Thermoelectric Generators
}

\author{
Jay Patel ${ }^{1 *}$, Manmohan Singh ${ }^{1}$ \\ ${ }^{1}$ Western Sydney University, Australia \\ *Corresponding author: Jay Patel: mymailmyid0011@gmail.com
}

\section{OPEN ACCESS}

Citation: Patel J., Singh M, (2021) Thermoelectric Generators. Open Science Journal 6(2)

\section{Received: $31^{\text {st }}$ October 2020}

Accepted: $2^{\text {nd }}$ February 2021

Published: $27^{\text {th }}$ May 2021

Copyright: (C) 2021 This is an open access article under the terms of the Creative Commons Attribution License, which permits unrestricted use, distribution, and reproduction in any medium, provided the original author and source are credited.

Funding: The author(s) received no specific funding for this work

Competing Interests: The author has declared that no competing interests exists.

\section{Abstract:}

Energy requirements across the world are increasing rapidly with industrialization and urbanization. Due to this increase in demand, economies had to come up with policies and pathways to shift from conventional mechanisms to energy-efficient machines. However, considering a change in demand patterns and the fact that a large amount of energy utilization goes to waste, waste energy is also being converted and utilized for more desirable forms. Other forms of energy examples include the smoke coming out of chimneys that can be utilized for harnessing thermal energy through thermo-electric generators which consequently increases the system efficiency. This study assesses silicon-germanium generators for converting this heat to electricity. Initially, a single module of thermoelectric generator has be made using $\mathrm{p}$ and n-type material, a conductive substance, and some ceramic materials. Ansys modules have been used to analyze the constructed geometry with custom materials. After performing the full model simulations, a comparative study has been presented in which effect of the material of conductive plate on the voltage difference has been studied.

Keywords: Energy, Thermoelectric Generators, Energy-efficient machines

\section{Introduction}

Ever since the start of the industrial revolution, electricity has been consumed at a rapid pace and the energy demand is at an all-time high. These past few decades have seen us use more energy than all of mankind's history combined and the majority share of that energy is being consumed in the form of electricity. To meet the demands of the world, we have so far relied majorly on fossil fuels. The steam power plants or gas power plants throughout the world use 
fossil fuel as their energy source. Not only it increases the harmful gases in the environment and causing global warming which is changing our climate drastically, but the fossil fuel resources are also depleting rapidly. 70 per cent of the fossil fuels had already been burned and their demand is still increasing. There is increased demand for fuel even though the countries are running out of reserves.

Knowing the importance of energy production and the lack of available resources to do so, the attention has been focused on renewable energy resources such as solar power, wind power, etc. Thermoelectric energy converters are also one of the above-mentioned alternatives to conventional ways of electricity generation.

\section{Thermoelectric effect}

The thermoelectric effect is defined as the direct conversion of the difference in temperature into voltage and similarly conversion of voltage into temperature based on the Seebeck Effect. (Lauck, Uyehara, \& Myers, 1963). Seebeck Effect was first introduced in 1821 and according to that if the two dissimilar metals are joint with each other at different temperature, there will be an electromotive forceand a resulting voltage between them. The electromotive force induces a current known as thermos current. The larger the temperature difference between the two metals the greater will be the value of electromotive motive force between them. (Lauck et al., 1963) The effect is reversible which means if there is a voltage between two joint dissimilar metals there is going to be a temperature difference between the two. This reverse effect was discovered in 1834 and is known as the Peltier effect. The difference between temperature or voltage is due to the properties of the material and this intrinsic property of the material is known as Seebeck Coefficient. It is defined as the measure of the magnitude of thermoelectric voltage when a temperature difference is applied across the material.

Generally, the Seebeck effect was geared for the metals but it has been observed over the years that semiconductors can also show this effect and more effectively as compared to the metals. These semiconductors based thermoelectric devices have been used in space crafts and other applications linked with cooling. (Mahan \& Sofo, 1996) Although their use as thermoelectric generators have been limited but since the demand for renewable energy is now at all-time high and they have been proposed as an excellent upcoming solution.

\section{Working principle of thermoelectric generators}

Thermoelectric generators work on the Seebeck principle. i.e. when two materials are exposed to different temperatures there is a resultant voltage between the two. Thermoelectric generators take heat input at one end of the material and then induce a voltage due to the difference in temperatures between them. There have been different materials that are being used in the thermoelectric generators and a majority of them are now using semiconductors. (Matsumoto et al., 2015) A schematic diagram of a thermoelectric generator is given below: 


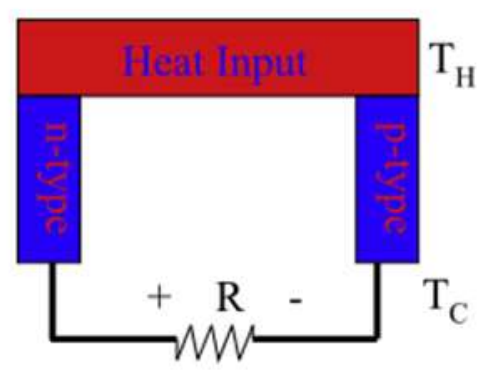

Figure 1: Schematic diagram of a thermoelectric Generator

\section{Literature review}

\section{Design of thermoelectric generators}

When it comes to the designing of thermoelectric generators, there are significant number parameters to be considered. For example, the type of material that can be used, the type of formation, and the type of optimization that can be incorporated. The thermoelectric generators that are currently being used are designed to utilize waste heat but they are not as efficient unless we provide them with their heat source which will make their use practically moot. The limitation of a thermoelectric generator is its conversion efficiency. We therefore aim to design thermoelectric generators that do not use their source of heat rather use waste heat.

The main objective is to correctly use the right material for the job. When it comes to the materials for Thermoelectric generators, the most effective to gauge the efficiency of the materials is by using the Seebeck coefficientwith three main categories as mentioned belo: (Ds, Mahajan, Anbalagan, \& Mallik, 2014) (Rohit, Manaswini, Kotebavi, \& S R, 2017)

-Semiconductors

Semiconductors are most promising when it comes to their use in thermoelectric generators. They are superior to metals when it comes to the construction of thermocouples because they have high Seebeck coefficient values and they range around 100 microvolts per centigrade. The ZT value or the heat absorbed in per unit area of the joint per second, a dimensionless parameter is greatly considered when it comes to choosing the material. For any material, ZT is found as follows:

$$
\mathrm{ZT}=\frac{\alpha^{2}}{\kappa} \sigma T
$$

Here, Alpha is the Seebeck coefficient, Sigma is the electrical conductivity, $\mathrm{k}$ is the thermal conductivity and $\mathrm{T}$ is the temperature of the material. The bigger the value of $\mathrm{ZT}$ better is the material for the generator most of the time. One of the ways the $\mathrm{ZT}$ value is increased is by making use of semiconductors that have high atomic mass, this reduces their thermal coefficient which in turn increases the overall value of ZT. The ZT materials which are considered good are more 
often than not heavily doped by heavy metals. (Jaziri et al., 2019) (Kim, Liu, Chen, Chu, \& Ren, 2015)

-Ceramics

Ceramics are also an alternate to semiconductors and they can also be used in the manufacturing of thermoelectric generators. The ceramics have better resistance against oxidation and are generally more stable as compared to the semiconductors which make them ideal for use in cases where longevity is required. They are less efficient than semiconductors but at the same time, they are more stable and resistant. (Ds et al., 2014)

-Polymers

The main idea behind using thermoelectric generators was to use less naturally available nonrenewable resources, while it at the core establishes that, the use of semiconductors is ironic since they are also hard to make and are made from rare elements. To counter this, there have been many polymers that have been produced that can exhibit the proper thermoelectric effect. They are flexible, they are produced at significantly less cost and they have shown enough potential to be worked on. For example segregated composite containing 2.6 vol\% CNTs and 5.1 vol\% Bi2Te3 exhibit the thermoelectric figure of merit ZT $=3 \times 10-$ 5 at room temperature (He et al., 2015)

Some ZT values of various materials are shown below:

Table 1: ZT values of various materials and their corresponding temperatures

\begin{tabular}{|c|l|l|l|}
\hline Sr. No & Material & ZT & Temperature $(\mathrm{K})$ \\
\hline 1 & BiSeo.5Te2.5 & 2.3 & Room temperature \\
\hline 2 & (BiSb)2Te3 & 1.4 & Room temperature \\
\hline 3 & Bi2Te2.7Se0.3 & 1.3 & Room temperature \\
\hline 4 & Bi0.Sb1.6Te3 & 1.3 & Room temperature \\
\hline 5 & P-type (BiSb)2Te3 & 1.2 & Room temperature \\
\hline 6 & Bi2(Te.Se)3 & 1 & Room temperature \\
\hline 7 & P-type(Bi0.26Sb0.74)2Te3+3\%Te ingots & 1.1 \\
\hline 8 & Bi-Sb-Te materials & 1.2 & \\
\hline 9 & Bi2Te3)0.25(Sb2Te3)0.75 & 2.8 & 350 \\
\hline 10 & Bi2Te2.85Se0.15 & 1.9 & 723 \\
\hline 11 & Bi0.5Sb1.5Te3 & 1.7 & 773 \\
\hline 12 & Bi2Te3-5\%Bi2Se3 & 1.9 & 693 \\
\hline 13 & Bi2Se3)(Bi2Te3)t-x & 1.6 & 723 \\
\hline 14 & Bi2Te3 & 1.9 & 713 \\
\hline 15 & Bi2Te2.85Se0.15 & 2.4 & 693 \\
\hline 16 & p type Bi2Te3/Sb2Te3 & 693 \\
\hline
\end{tabular}




\section{Open Science Journal}

Table 2: Different materials and their highest ZT values and their corresponding temperatures

\begin{tabular}{|c|l|c|c|}
\hline Sr. No & Material & ZT & Temperature $(\mathrm{K})$ \\
\hline 1 & Si0.8Ge0.2 & 0.66 & 1073 \\
\hline 2 & BaUO3 & 1.8 & 900 \\
\hline 3 & SiC/B4C+PSS & 1.75 & 873 \\
\hline 4 & Mg2Si & 0.86 & 862 \\
\hline 5 & Fe0.9Mn0.1Si2 & 1.31 & 773 \\
\hline 6 & Zn4Sb3 & 1.2 & 469 \\
\hline 7 & Ti9BiTe6 & 0.86 & 590 \\
\hline 8 & CuxSn1Sn4 & 0.6 & 570 \\
\hline 9 & Graphite & 0.54 & 393 \\
\hline 10 & Sb2-xBixTe & 0.93 & 300 \\
\hline 11 & PbTe & 0.87 & 293 \\
\hline 12 & Pbt-xMnxTe & 1.6 & 700 \\
\hline 13 & BiCuSeO & 0.9 & 923 \\
\hline 14 & ln4Se3 & 1.48 & 705 \\
\hline 15 & Snse single crystal & 2.6 & 923 \\
\hline 16 & 3,4 -Ethylenedioxythiophene & 0.42 & Room temperature \\
\hline
\end{tabular}

An experimental schematic diagram of a thermoelectric generator is as follows

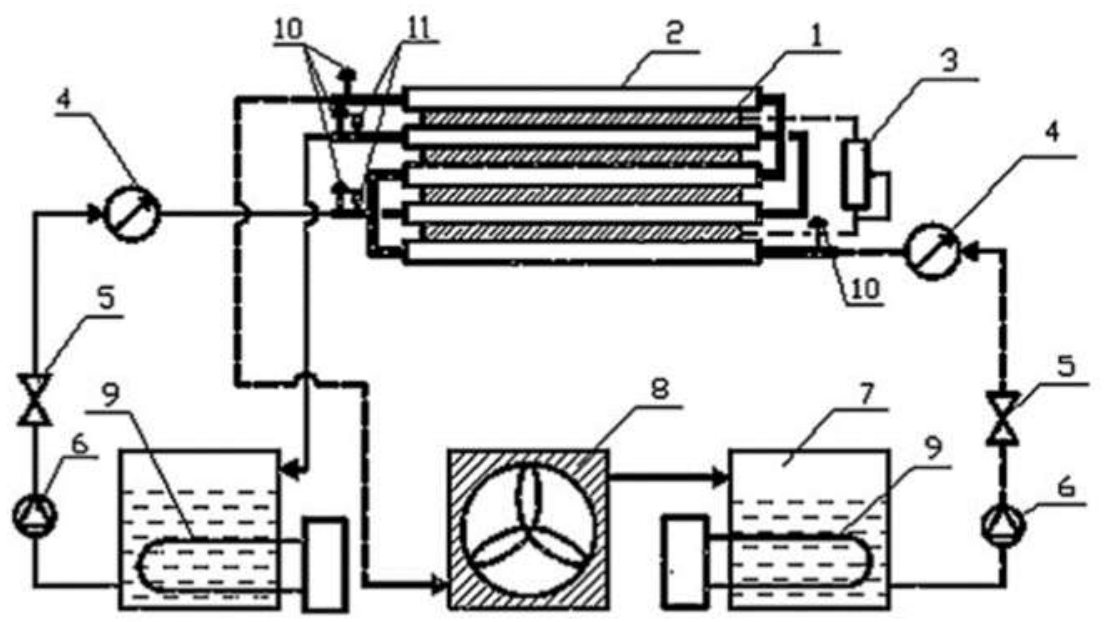

1-Thermoelectric module 2-Plate heat exchanger 3-Load resistor 4Volumetric flowmeter S-Valve 6-Punp 7-Fluidbath 8-Air cooler 9-Electrical heater 10-Temperature sersor 11-Pressure sensor

Figure 4: Schematic of a standard thermoelectric Generator 


\section{Heat sources for thermoelectric generators}

As mentioned previously, the heat sources for these generators are to be either existing naturally or in the form of waste heat. These generators are not efficient to the extent where they can be provided with their own heat energy. To comply with this, there are the following heat sources that can be used to power the thermoelectric generators. They can be categorized into three main categories and they are explained as follows:

\section{Biomass}

Biomass can be defined as the range of organic materials that can be used to create energy. Currently, biomass is being used a large commercial as well as noncommercial scale in different applications. The main area is te production of heat through combustion of biomass that produces a lot of redundant heat which can be used by the proposed generator to harness energy. (Joshi, 2013)

\section{Solar Power}

Solar power is another way in which thermoelectric generators can be used. They are designed in a way that they can catch the majority of the sunlight and focuses on a certain area with the help of a parabolic mirror etc. that way it can create a temperature differential and then the generator can use the temperature difference. A simple thermoelectric solar generator is shown in the figure below: (Shakouri, Norton, \& McNally, 2014) (Kraemer et al., 2011)

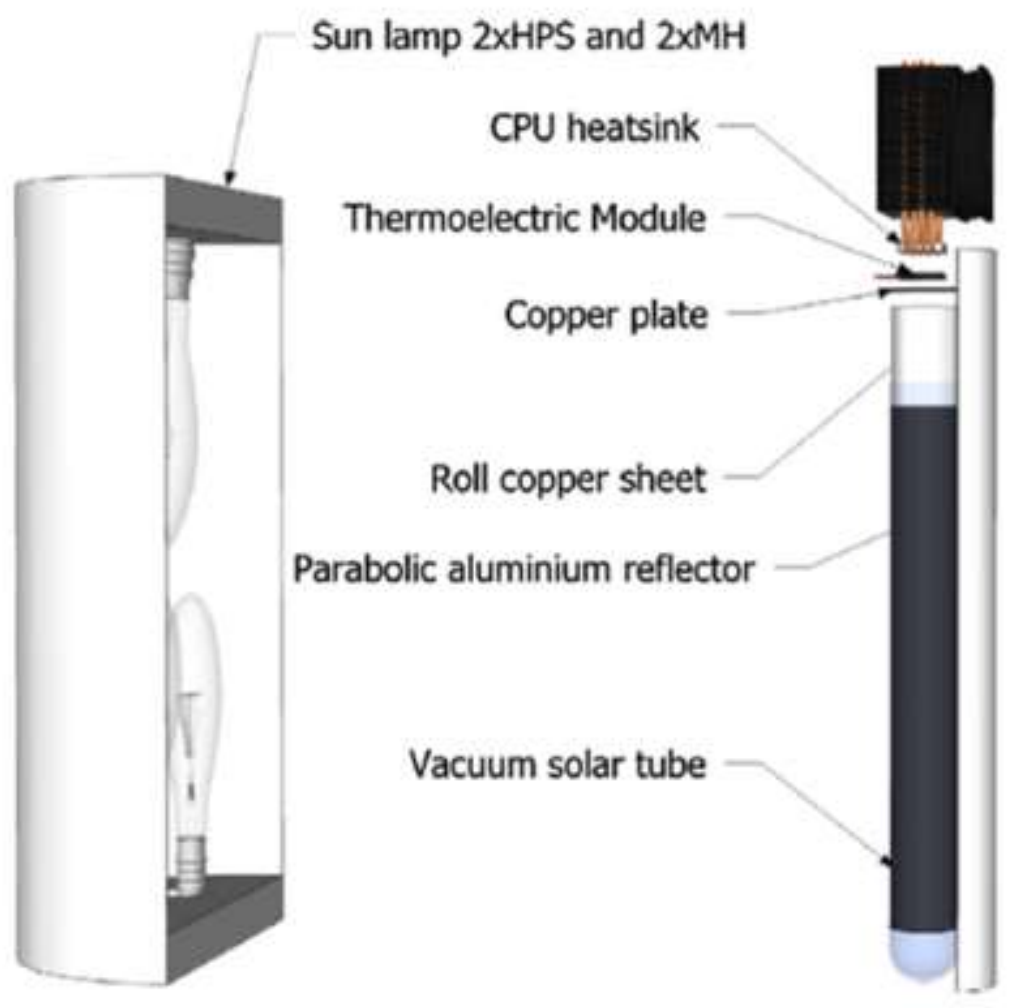

Figure 5: Schematic diagram of a solar-powered thermoelectric Generator 
Earth's temperature difference

There are situations where we cannot make use of the other two types of heat sources we can use the earth's temperature difference between the layers to our advantage. (Olsten \& Mohagheghi, 2017) This type of generator can be used as a portable generator for remote area applications etc. the schematic of standard earth powered thermoelectric generator is shown in the figure below:
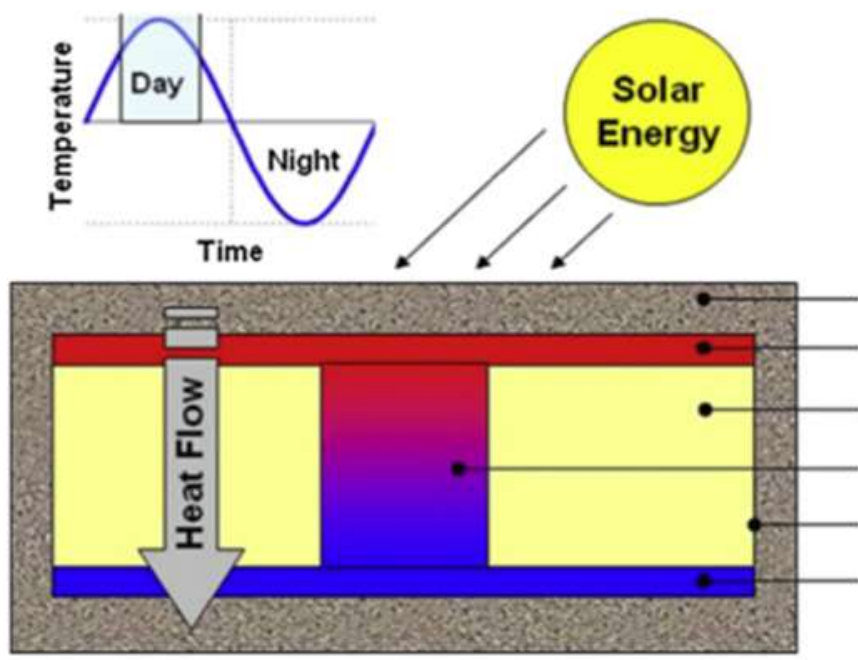

Soil

Hot Side Heat Plate

Thermal Insulation

Thermopile

Environmental Barrier

Cold Side Heat Plate

Figure 6: Schematic diagram of a thermoelectric generator powered by the earth's temperature differential

\section{Application of thermoelectric generators}

Thermo-electric generators have numerous applications in Space where they can be used to convert heat from radio waves into electricity. Further automobile engines are very common application of these generators where the exhaust gases and steam can be treated to utilize the waste heat recovery. In buildings, a thermoelectric generator can use the heat to power another device that can preheat the water increasing the overall efficiency of the system. Similarly, stoves and refrigerators can have secondary thermoelectric generators to increase their overall efficiency. (Champier, 2017)

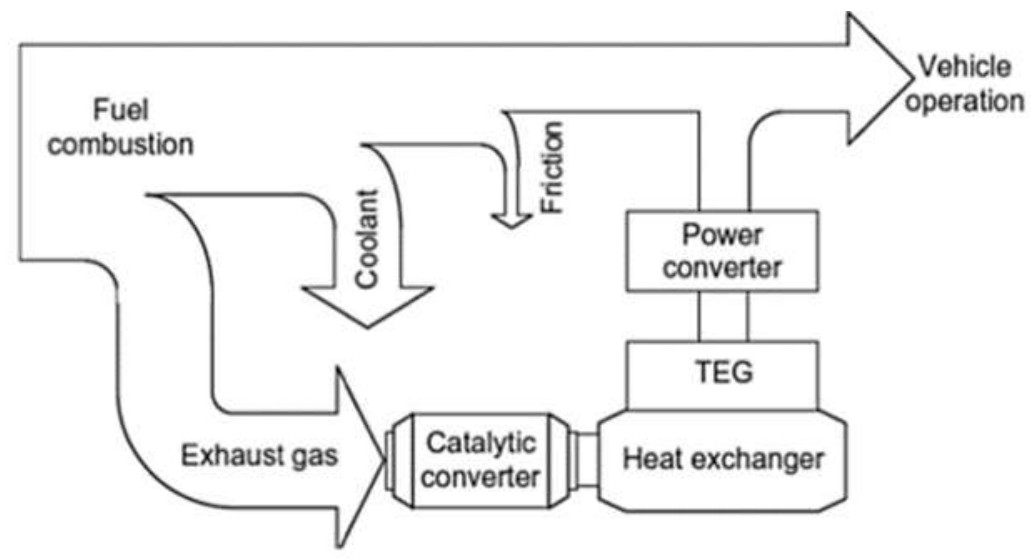

Figure 7: Engine heat recovery system with Thermoelectric generator 


\section{Objectives}

The study has the following objectives:

- To model a single unit TEG Module

- To model the assembly of the module by correctly making the assembly and assigning the right material to the right part

- To perform the electrothermal analysis on full as well as a single module.

- To get the comparative results of different conduction plates to study the effect of changing the conductive plate material on the voltage difference.

- To deduce the relation of material of conductive plate on to the power

\section{Methodology}

\section{Modeling}

The first step in any of the simulation-based analysis is the modeling of the accurate and the best possible geometry. This step is very crucial because if the geometry is not designed properly, any change at post analysis stage will take significantly larger consuming time. For this purpose, it was ensured that the design is properly set up for performing the analysis on it. In our case, the SOLIDWORKS was used for the $3 \mathrm{~d}$ modeling as well as the assembling of the multiple modules of $\mathrm{p}$ and $\mathrm{n}$ junction. The following parts were modeled in this case.

This study analyzes the modelling of different conductive materials and the custom plates on voltage and power production of the thermoelectric generators. Two different materials i.e. copper and steel are used to perform the analysis on ANSYS with details as mentioned below:

\section{Single Unit Modeling}

First of all, a single unit was modeled so that this model can be used to make an entire assembly.

\section{Insulation Plate}

Insulation plate was modeled and applied at the top and the bottom of the module. This served as a heat source in the first case.

\section{Conductive Plate}

Conductive plate design is very crucial. The circuit should be properly designed based on the attachment of this plate with the correct $\mathrm{p}$ and n-type legs.

Connecting the circuit

The circuit was completed using the conductive plate correctly so that all could be connected in series to produce the net effect of the assembly of single modules.

Load resistance

Load resistance was modeled to see the trend of potential on it. 
P-Type

The dimension of the P-type is the same as that of n-type.

N-Type

The dimension of the n-type is the same as that of p-type.

Table 3: Dimensions of the Geometry

\begin{tabular}{|l|c|}
\hline \multicolumn{1}{|c|}{ Parameter } & Dimension (mm) \\
\hline Cross section of P-type & $2{ }^{*} 2$ \\
\hline Cross section of N-type & $2{ }^{*} 2$ \\
\hline Length of P-type & 4 \\
\hline Length of N-type & 4 \\
\hline Ceramic plate cross section & $15.15^{*} 18$ \\
\hline Ceramic plate width & 1.5 \\
\hline Copper plte cross section & $2 * 4.5$ \\
\hline Copper plate width & 0.1 \\
\hline
\end{tabular}

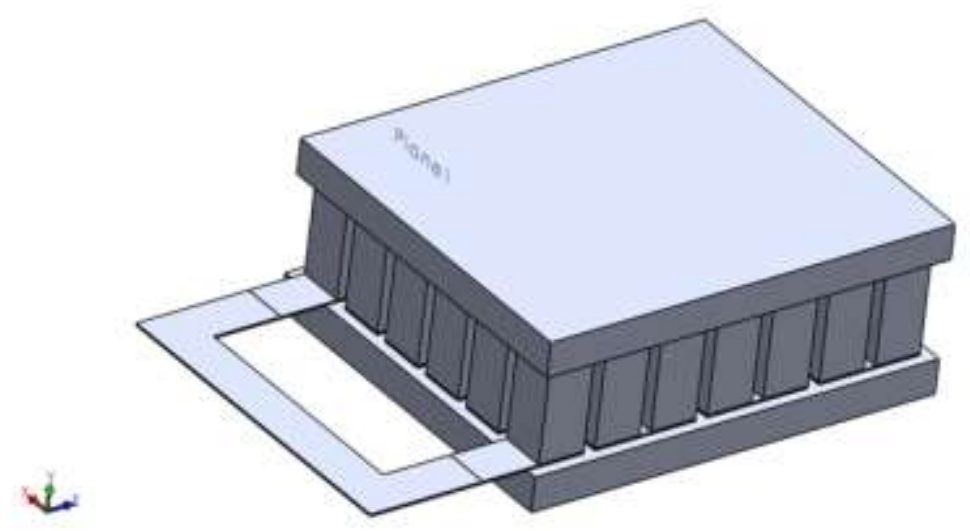

Figure 8: Geometry construction of the Thermoelectric generator including ceramic plate

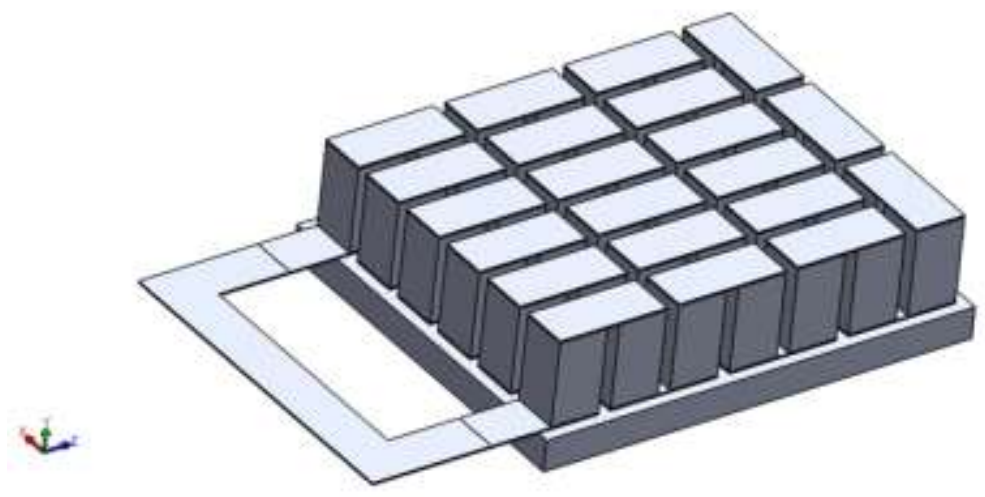

Figure 9: Geometry construction of the Thermoelectric generator excluding ceramic plate 


\section{Thermo-electric analysis}

After the model was ready, it was exported to Ansys to perform thermoelectric analysis. For this purpose, materials are to be added. In this case, silicon germanium material was used. Copper was used in the first case and then steel was used as a conduction plate in the second case. For this analysis, boundary conditions were defined very accurately. To perform this analysis, hot and cold-sided temperatures were applied and zero voltage was given to ground the connection and to analyze the flow of current after the analysis has been performed. Full Model Analysis

For the first case, when the model of the full module was ready, the details of which are given in the table, it was exported to Ansys to perform thermoelectric analysis. Materials with seed back coefficients were added to the engineering sources. Copper was used in this case as a material of conduction plate. For this analysis, boundary conditions were defined very accurately. To perform this analysis, hot and cold-sided temperatures were applied and zero voltage was given to ground the connection and to see the flow of current after the analysis has been performed.

\section{Model preview of ANSYS}

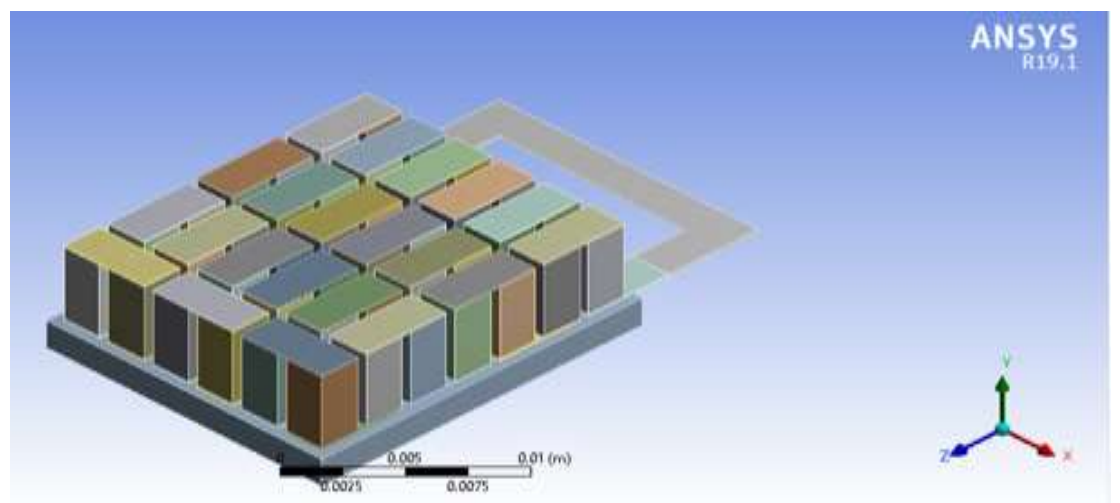

Figure 10: Model preview for full model case

\section{Meshing preview}

As the geometry is rectangular, square-shaped mesh is generated and fits perfectly into the geometry

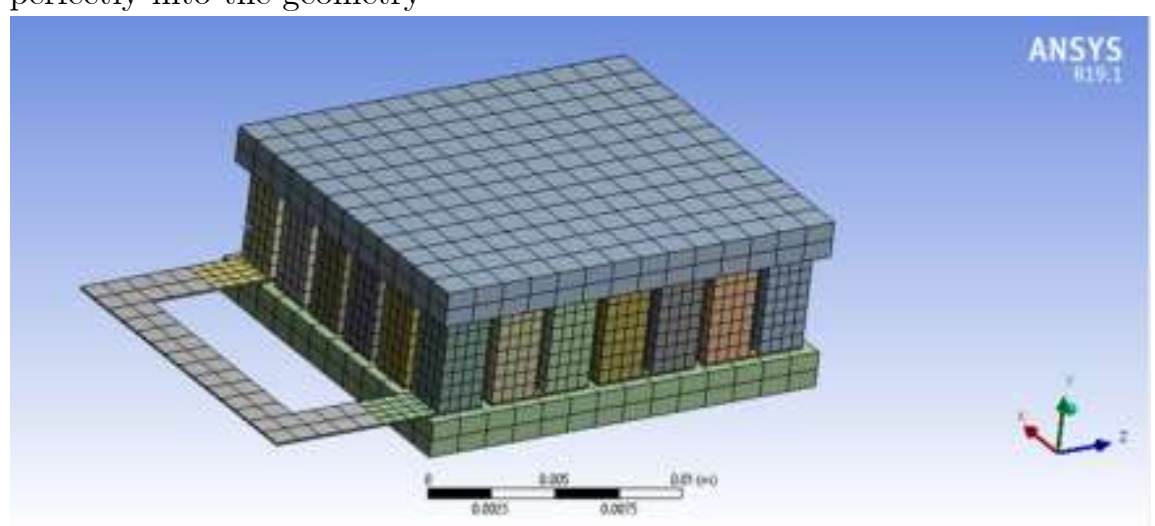

Figure 11: Meshing details for full model case 
For checking the grid independence, targeted space of the CFD model is divided into a finite number of grids for numerical analysis and an optimal design has been achieved to obtain accurate results. The grid resolution was calculated by applying the characteristic length. CV(RMSE) and $\mathrm{R}^{2}$ were applied as the criteria for optimal grid. The grid convergence index (GCI) was calculated to verify the suitability of the proposed method. As a result, all of the optimal grid resolution derived from the proposed method was evaluated as the optimal condition.

\section{Boundary conditions of full model analysis}

The details of the boundary conditions are given below. The temperature is applied on the top surface with a higher value and the bottom surface with a lower value. Similarly, a zero voltage is applied as well as can be seen in the figure.

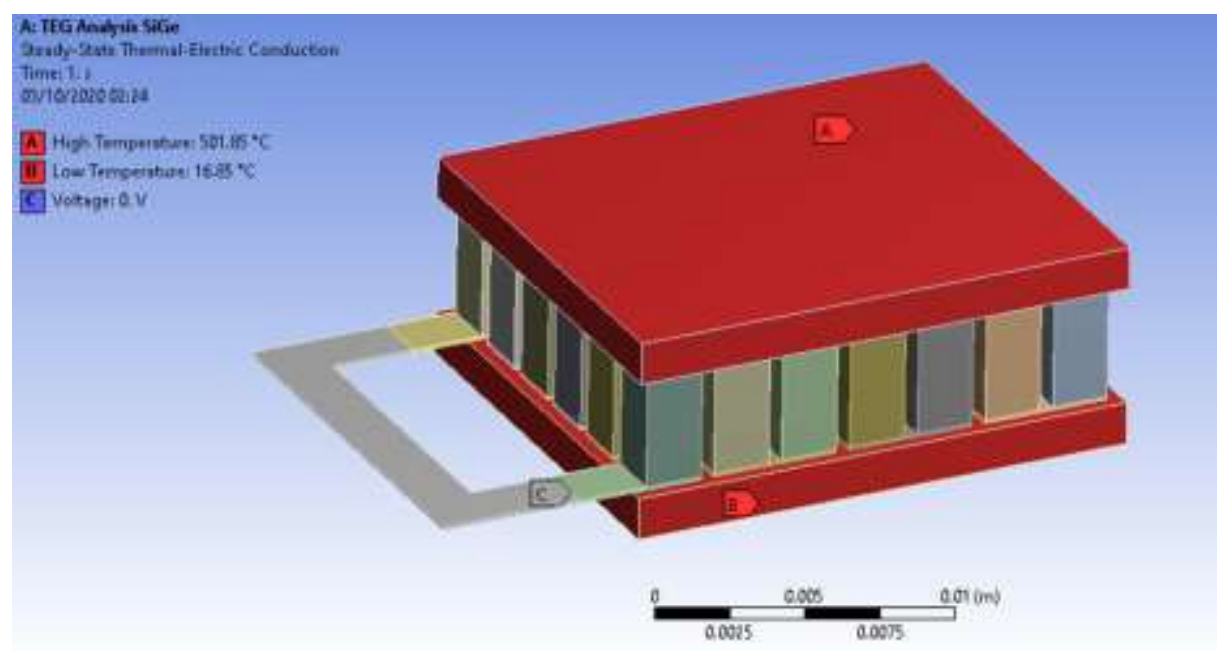

Figure 12: Boundary conditions for full model case 


\section{Results of full model analysis}

\section{Total heat flux}

The heat flux is maximum in the region in between the two plates of insulation as can be seen with a lighter color in the following contour.

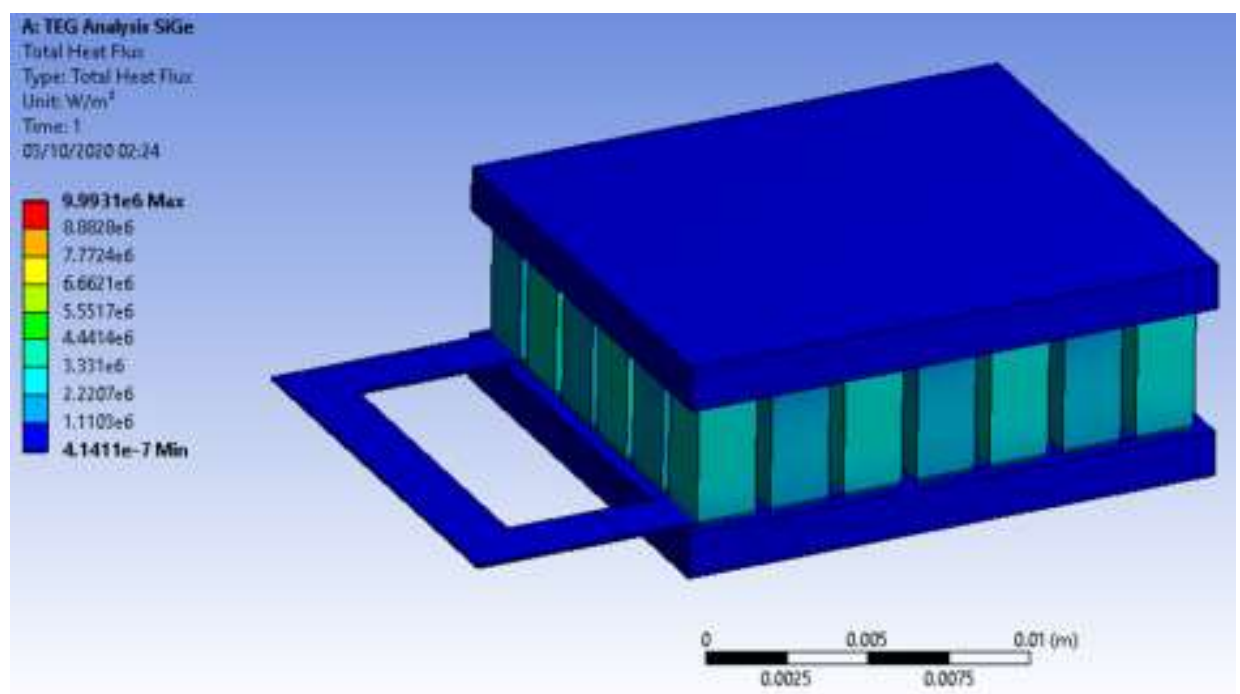

Figure 13: Total Heat Flux for full model case

\section{Temperature distribution}

One interesting thing to note in this contour is that the temperature of the source is less than legs of the module that have a higher temperature. The main reason is the insulating nature of the outer plate due to which their temperature doesn't go much higher as the case in semiconductors

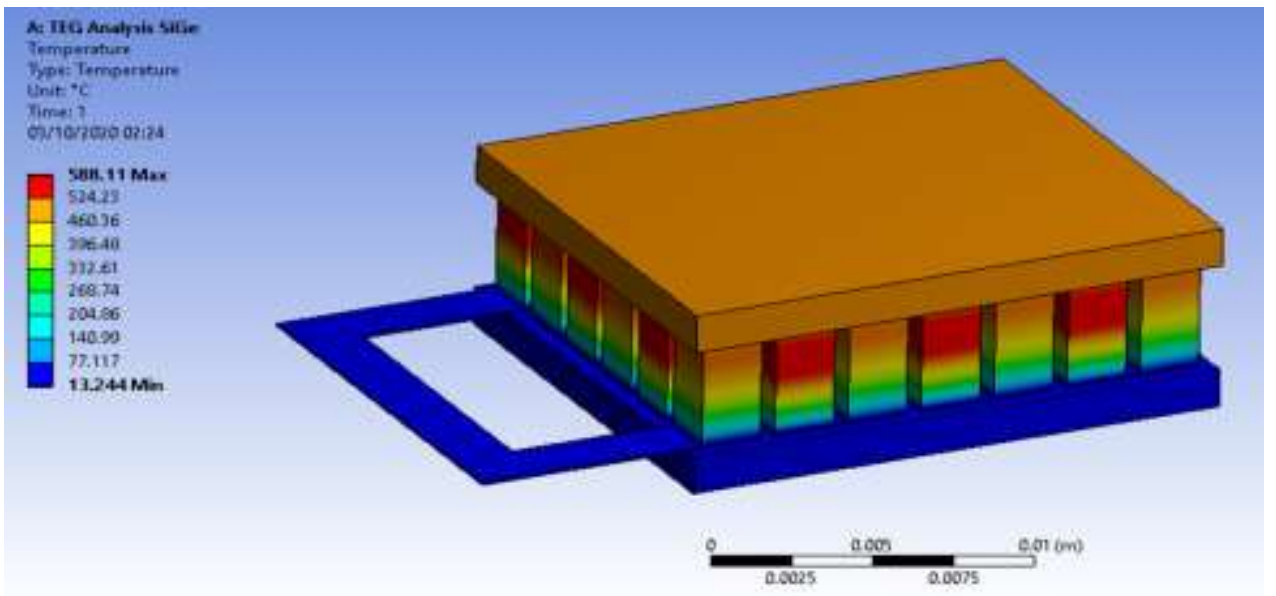

Figure 14: Temperature Distribution for full model case 


\section{Electric voltage}

The potential difference across each $\mathrm{p}$ and n-type junction can be observed in the following figure.

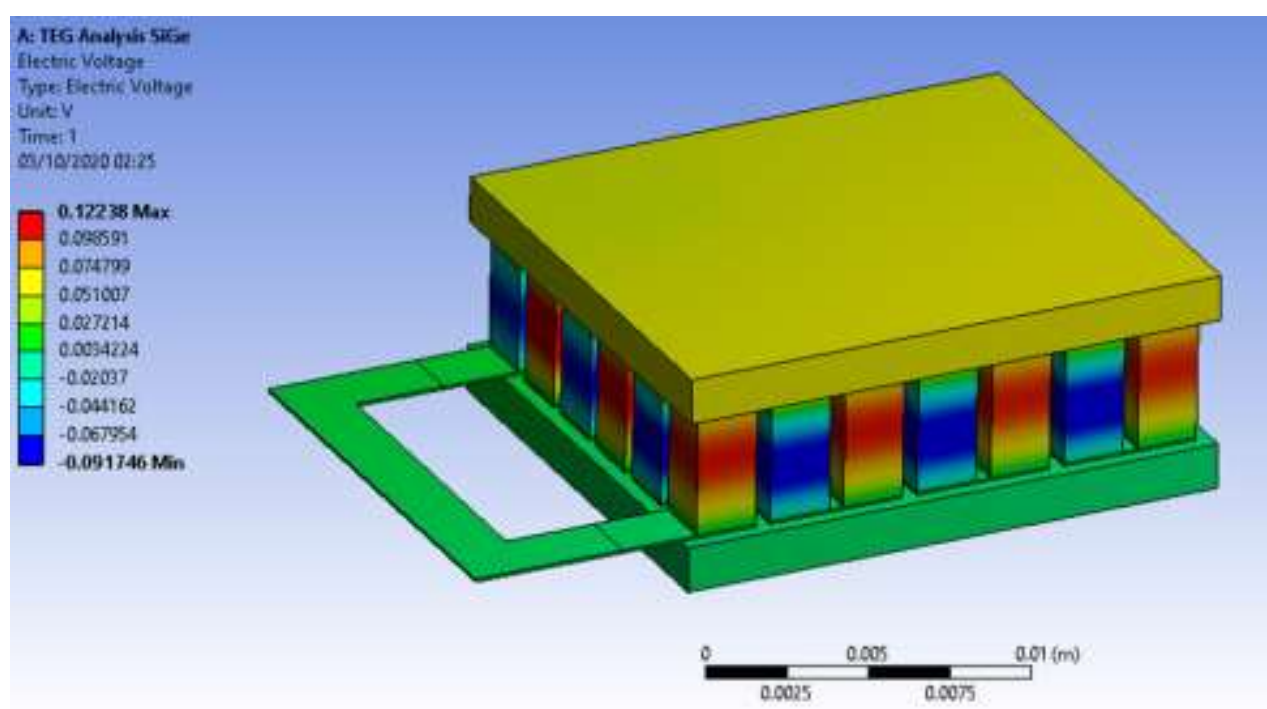

Figure 15: Electric Voltage for full model case

\section{Total current density}

In this case, maximum current density occurs on the conduction plate at the base
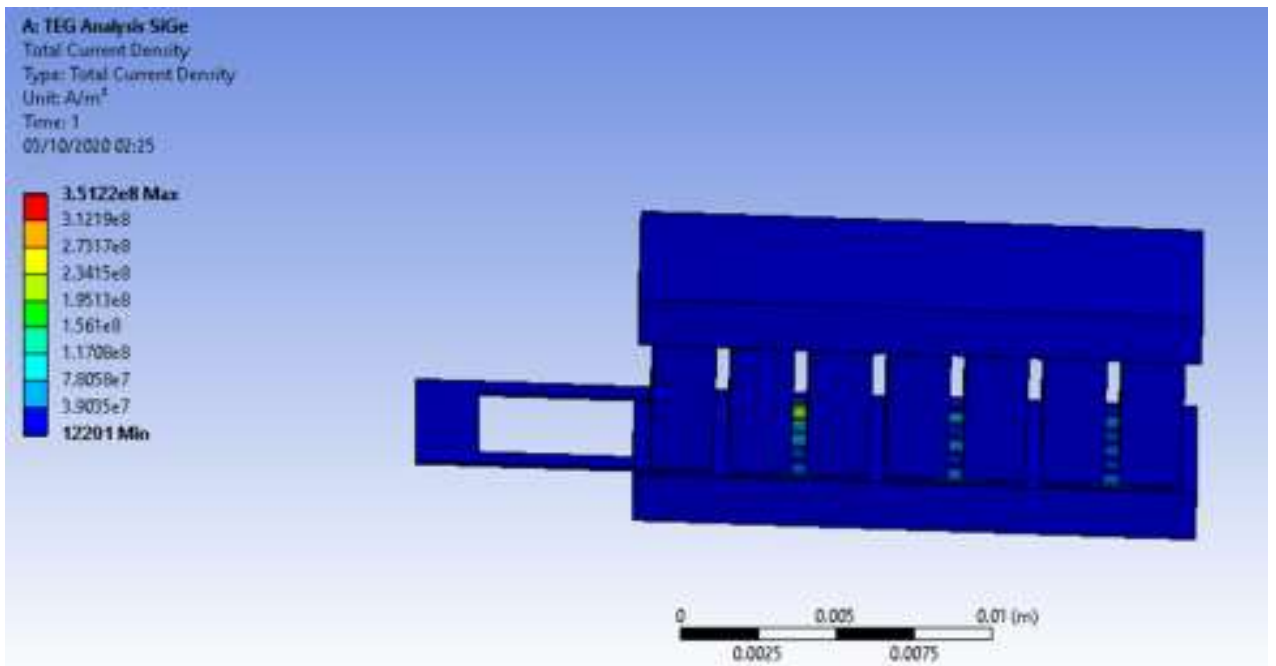

Figure 16: Total current density for full model case

\section{Electric voltage along with load}

The potential difference across the load resistance can be observed in the following figure. As it can be seen that potential on one edge is greater than the other which means that a potential difference has developed which can be used to extract the power. 


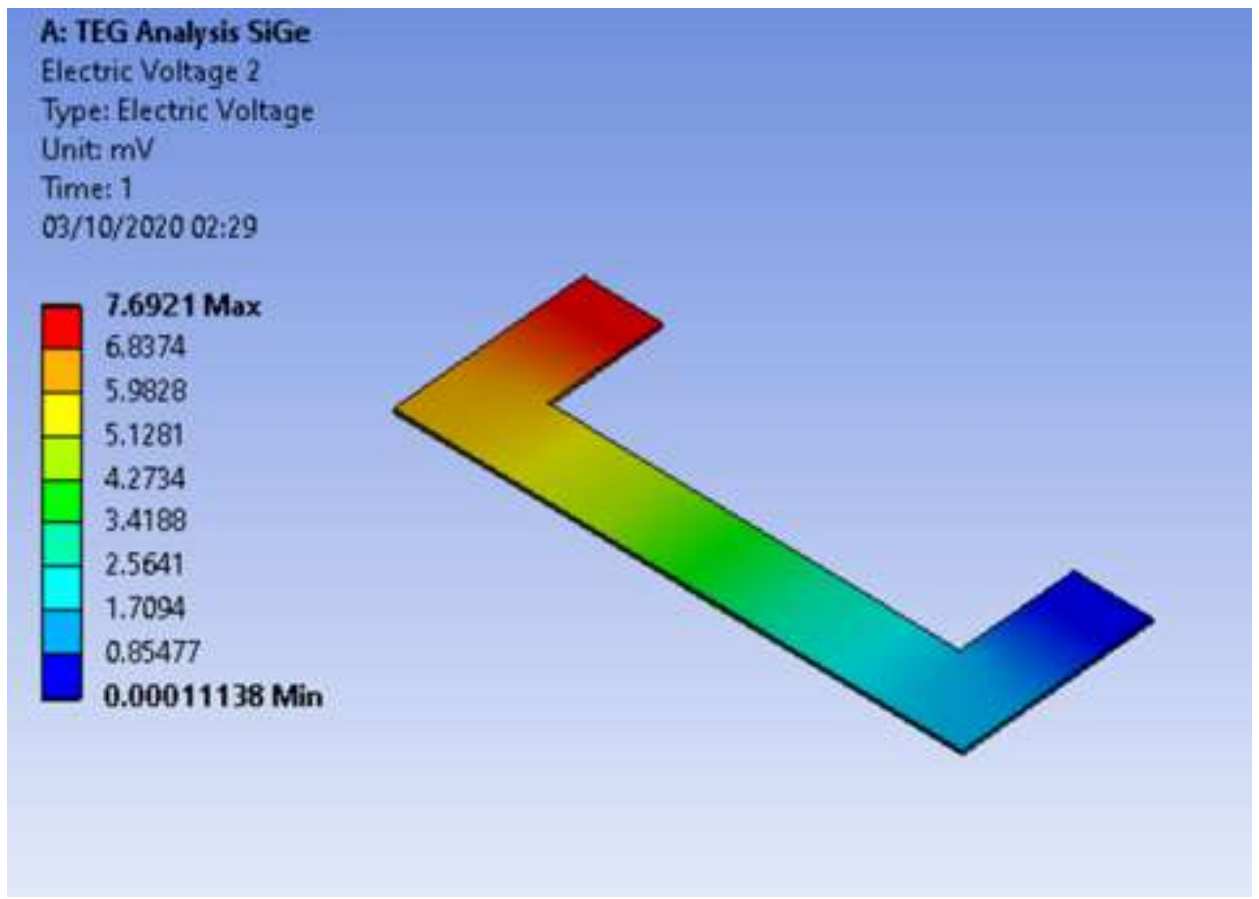

Figure 17: Voltage across the load for full model case

Heat absorbed

This is the reason for the lower potential difference because not much heat could reach the conduction plate.

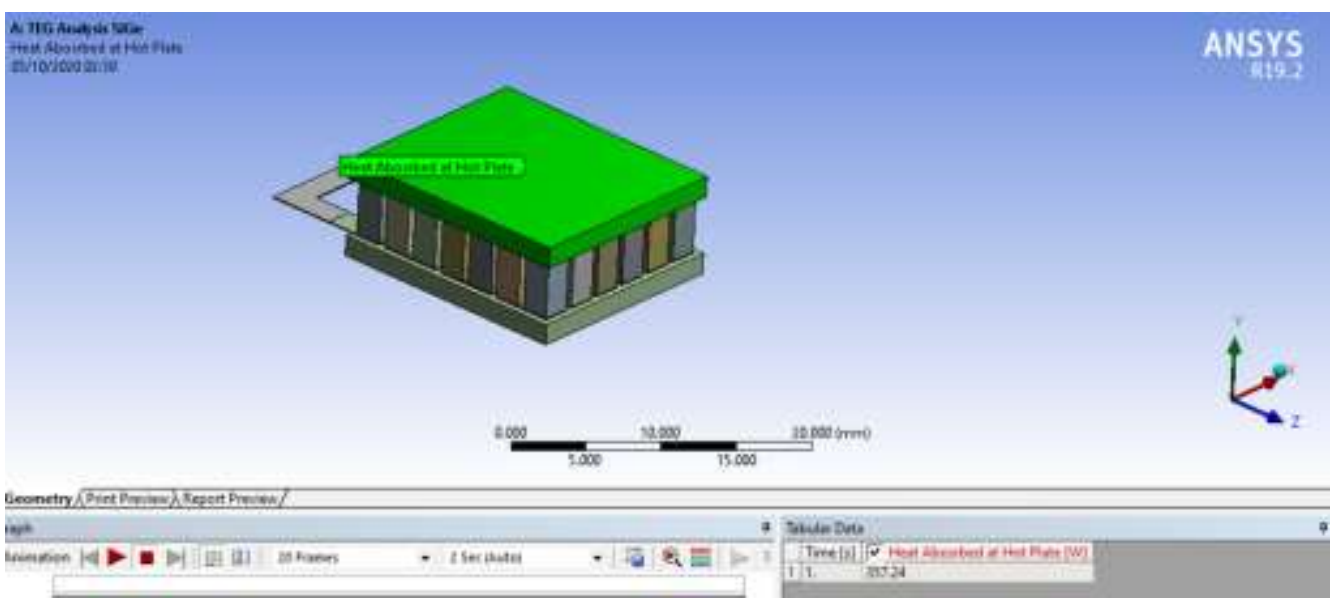

Figure 18: Heat Absorbed for full model case 
Single unit analysis: Copper alloy as conduction plate

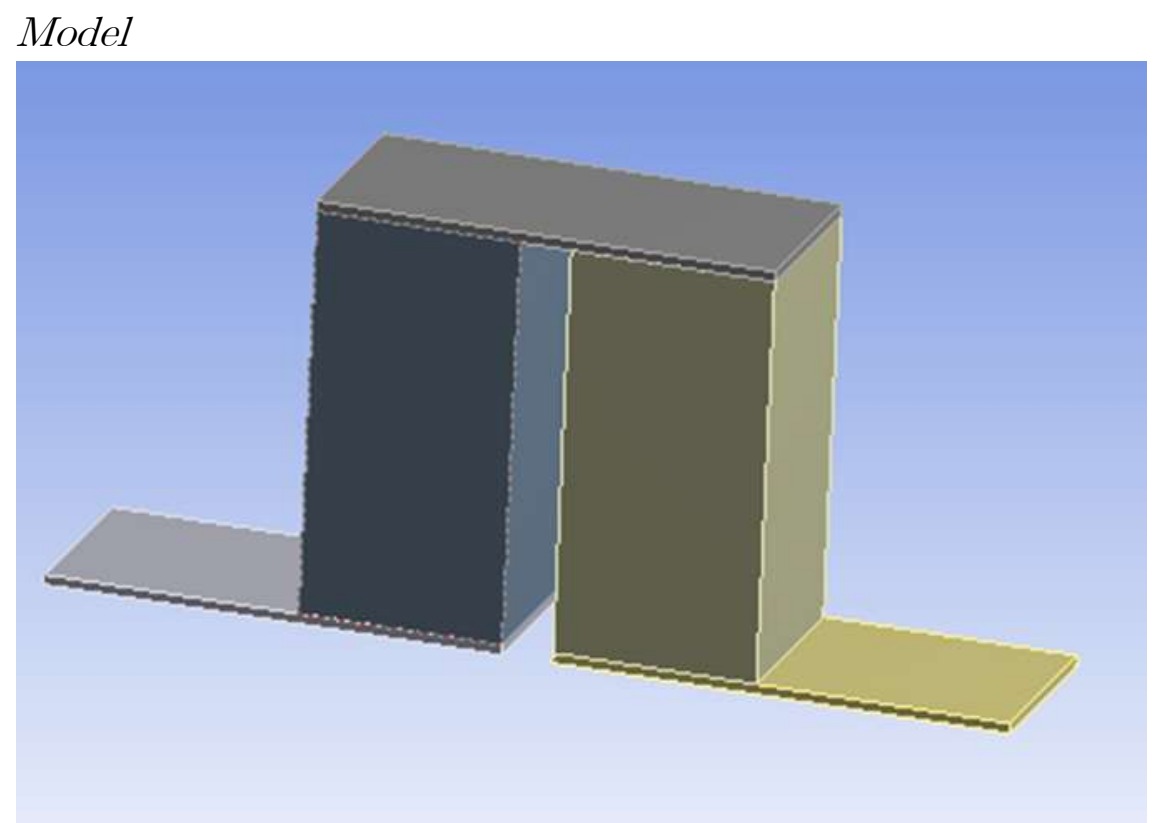

Figure 19: Model Information for COPPER ALLOY AS CONDUCTION PLATE

\section{Meshing information}

As the geometry is rectangular, square-shaped mesh is generated and fits perfectly into the geometry.

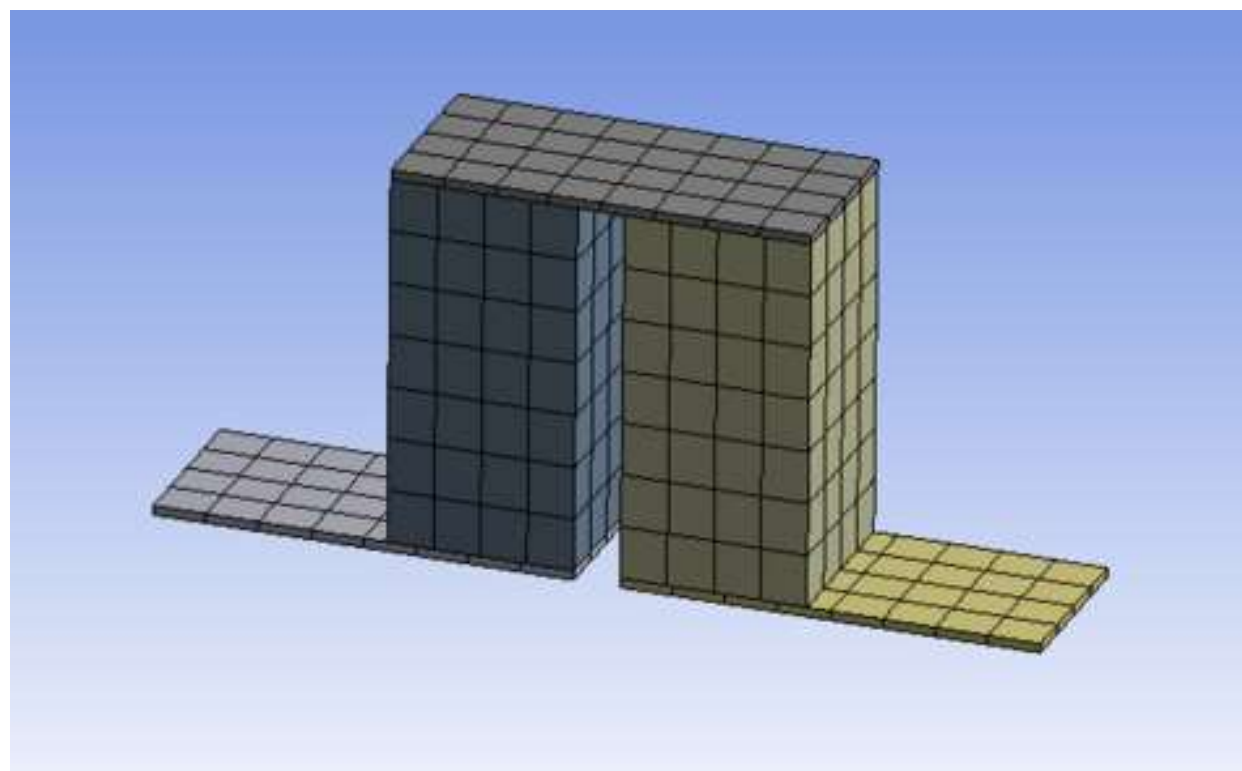

Figure 20: Meshing Details for COPPER ALLOY AS CONDUCTION PLATE 


\section{Boundary conditions}

The details of the boundary conditions for single module analysis are given below. The temperature is applied on the top surface, not on the ceramic this time, with a higher value and on the bottom surface with a lower value. Similarly, a zero voltage is applied as well as can be seen in the figure. In this case, the convection coefficient was also added on all the faces where the boundaries were not given.

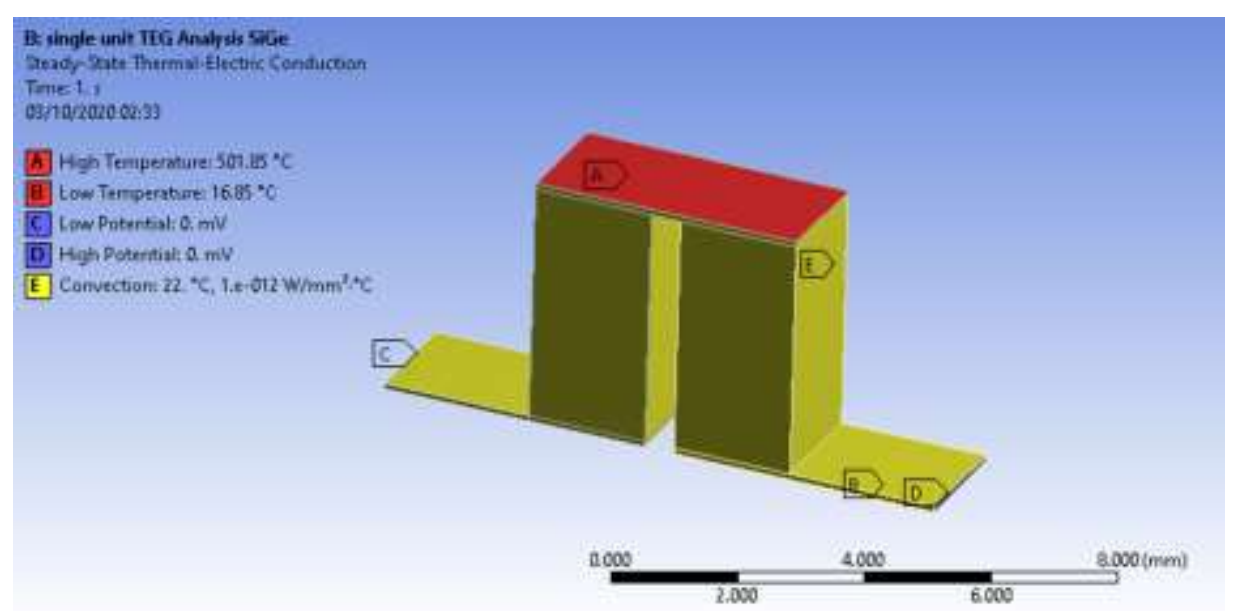

Figure 21: Boundary Conditions for COPPER ALLOY AS CONDUCTION PLATE

\section{Temperature distribution}

In this case, the maximum temperature is on the surface where the heat was applied and the minimum on the base as can be seen clearly from the given figure. The maximum is $502.72^{\circ}$ Celsius.

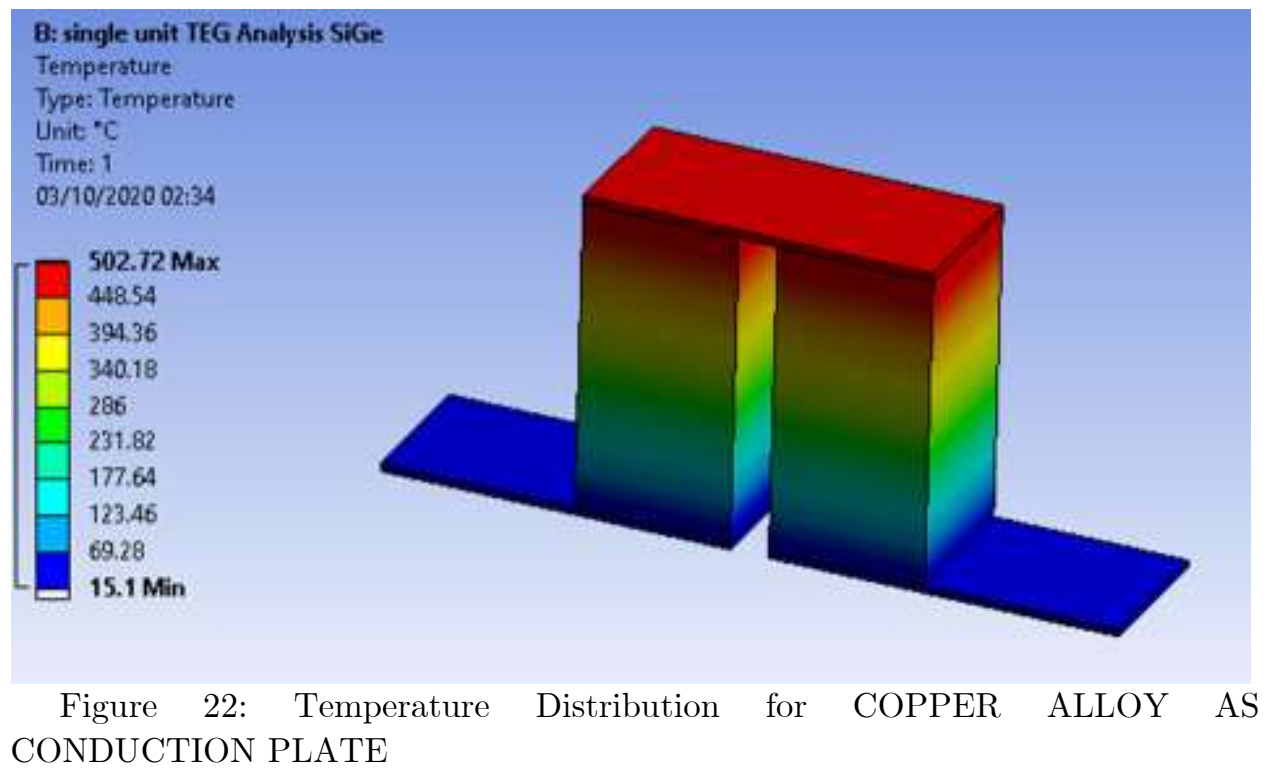




\section{Total heat flux}

Heat flux is from top to bottom from hot plate to cold plate and the values can be seen in the legend displayed.

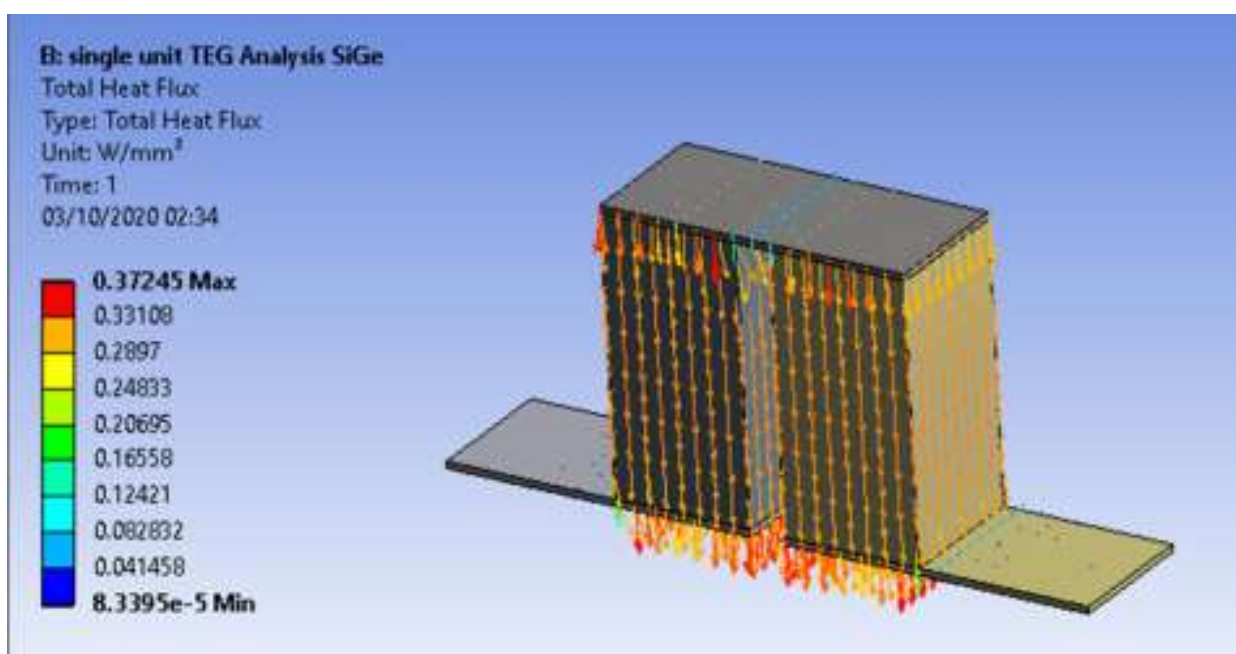

Figure 23: Total Heat Flux for COPPER ALLOY AS CONDUCTION PLATE

\section{Electric voltage}

As it can be seen that potential on one edge of the p-type is different than the other which means that a potential difference has developed which can be used to extract the power. The reddish region indicates the high potential while the bluish region indicates the lower potential.

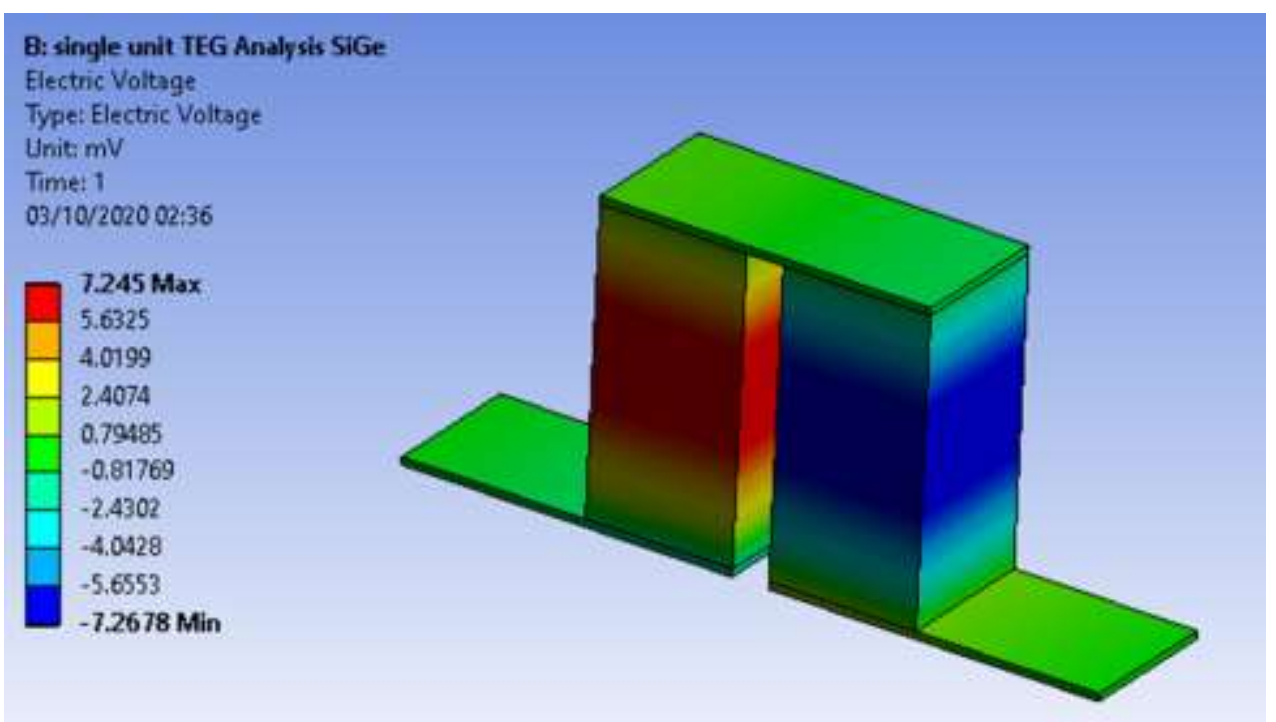

Figure 24: Electric Voltage for COPPER ALLOY AS CONDUCTION PLATE

\section{Current density}

The current is maximum on the edges and middle of the conduction plate and the direction is from p-type to n-type 


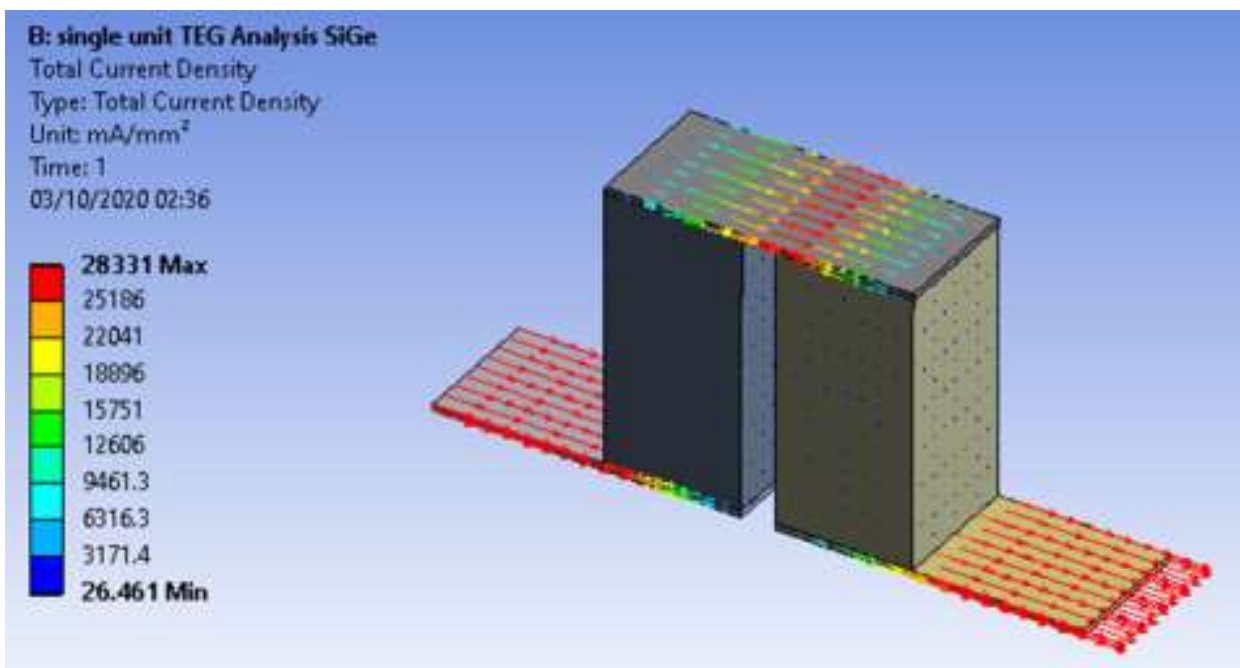

Figure 25: Total Current Density for COPPER ALLOY AS CONDUCTION PLATE

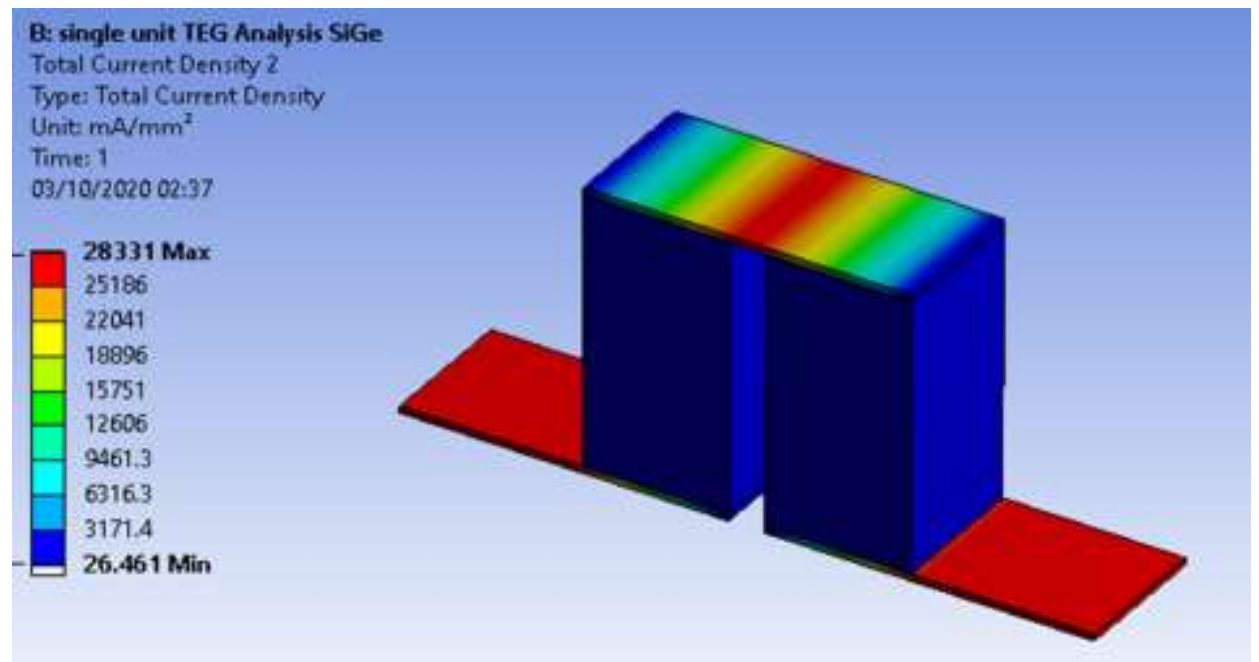

Figure 26: Total Current Density for COPPER ALLOY AS CONDUCTION PLATE

\section{Single Unit Analysis: Steel Alloy as conduction plate}

In this case, the boundary conditions are similar to the previous, the only difference is the material of the conduction plate.

\section{Temperature distribution}

In this case, the maximum temperature is on the surface where the heat was applied and the minimum on the base as can be seen clearly from the given figure. The maximum is $502.03^{\circ}$ Celsius. 


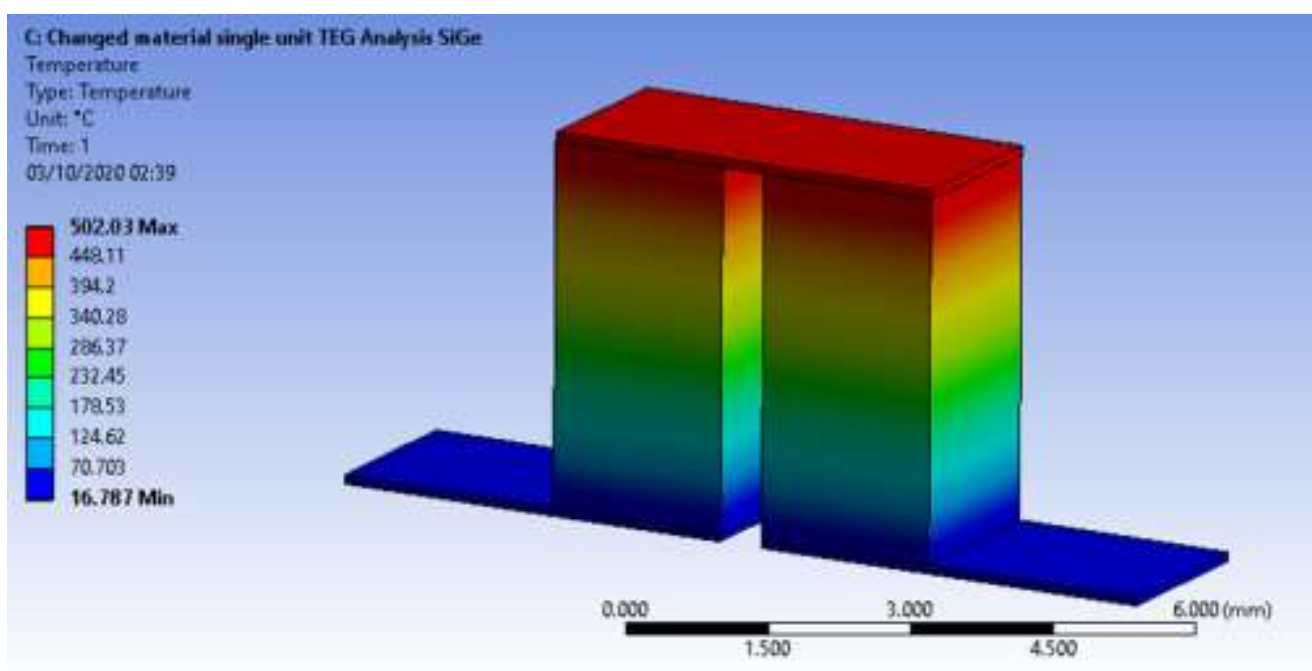

Figure 27: Temperature for STEEL ALLOY AS CONDUCTION PLATE

\section{Total heat flux}

Heat flux is from top to bottom from hot plate to cold plate and the values can be seen in the legend displayed. In this case, the maximum value is lesser as compared to the previous.

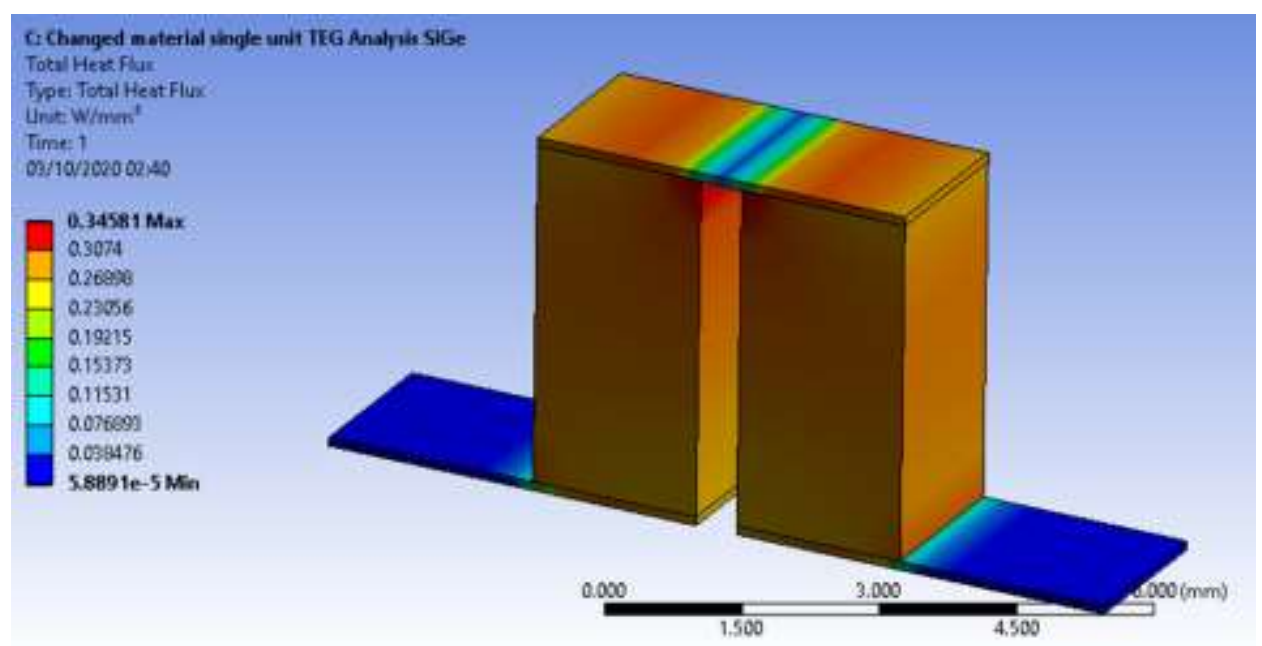

Figure 28: Total Heat Flux in contour view for STEEL ALLOY AS CONDUCTION PLATE 


\section{Total heat flux}

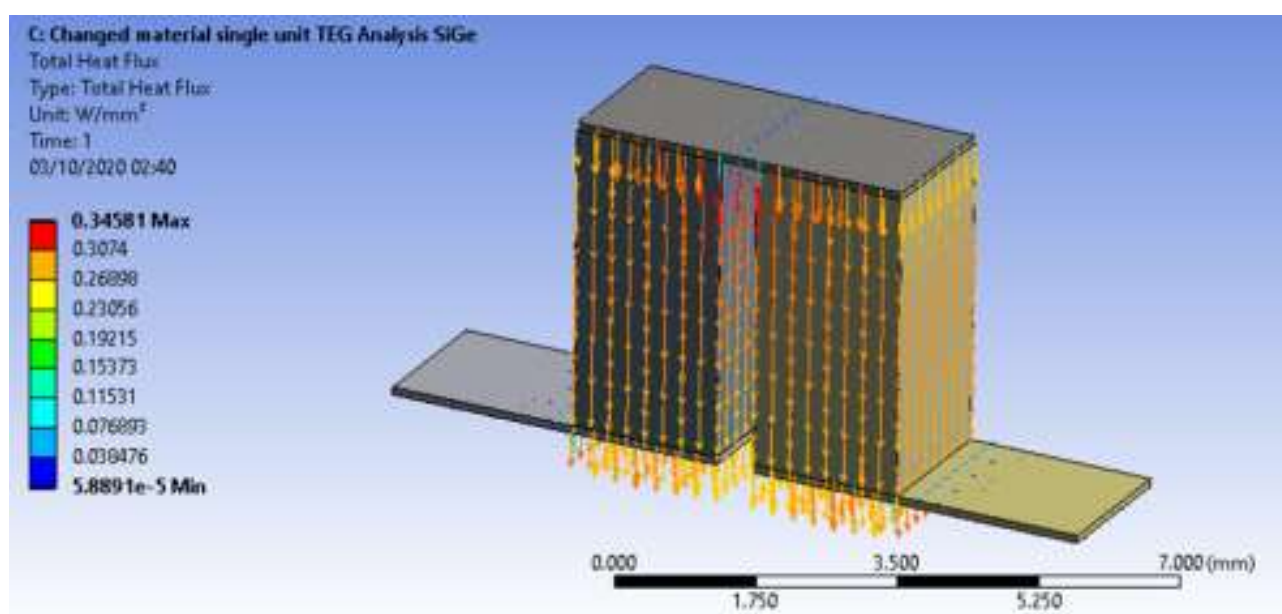

Figure 29: Total Heat Flux for STEEL ALLOY AS CONDUCTION PLATE

\section{Electric voltage}

As it can be seen that potential on one lower edge of the p-type is higher than the other which means that a potential difference causing the power availability has been developed across. The reddish region indicates the high potential while the bluish region indicates the lower potential. In this case, the maximum value is greater and distribution is different as well as compared to the previous case.

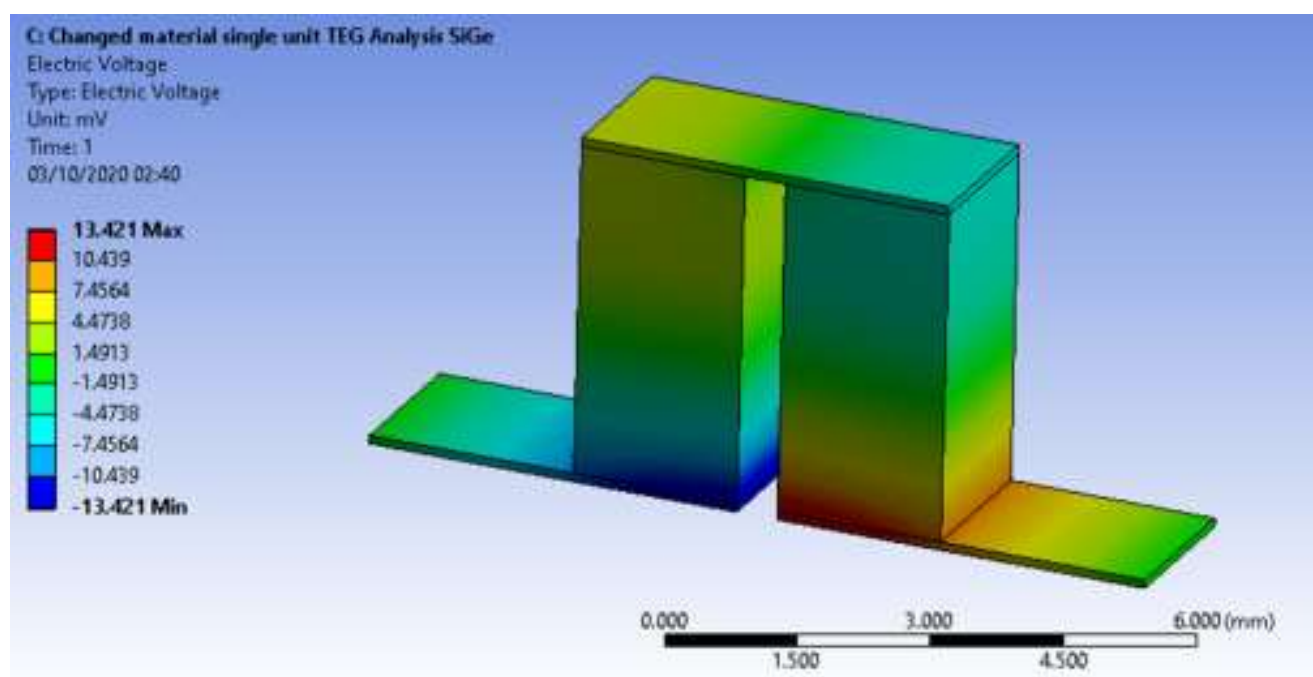

Figure 30: Electric Voltage for STEEL ALLOY AS CONDUCTION PLATE

\section{Total current density}

The current is maximum on the edges and middle of the conduction plate and the direction is from p-type to n-type. The maximum value, in this case, is lesser as compared to the previous case. 


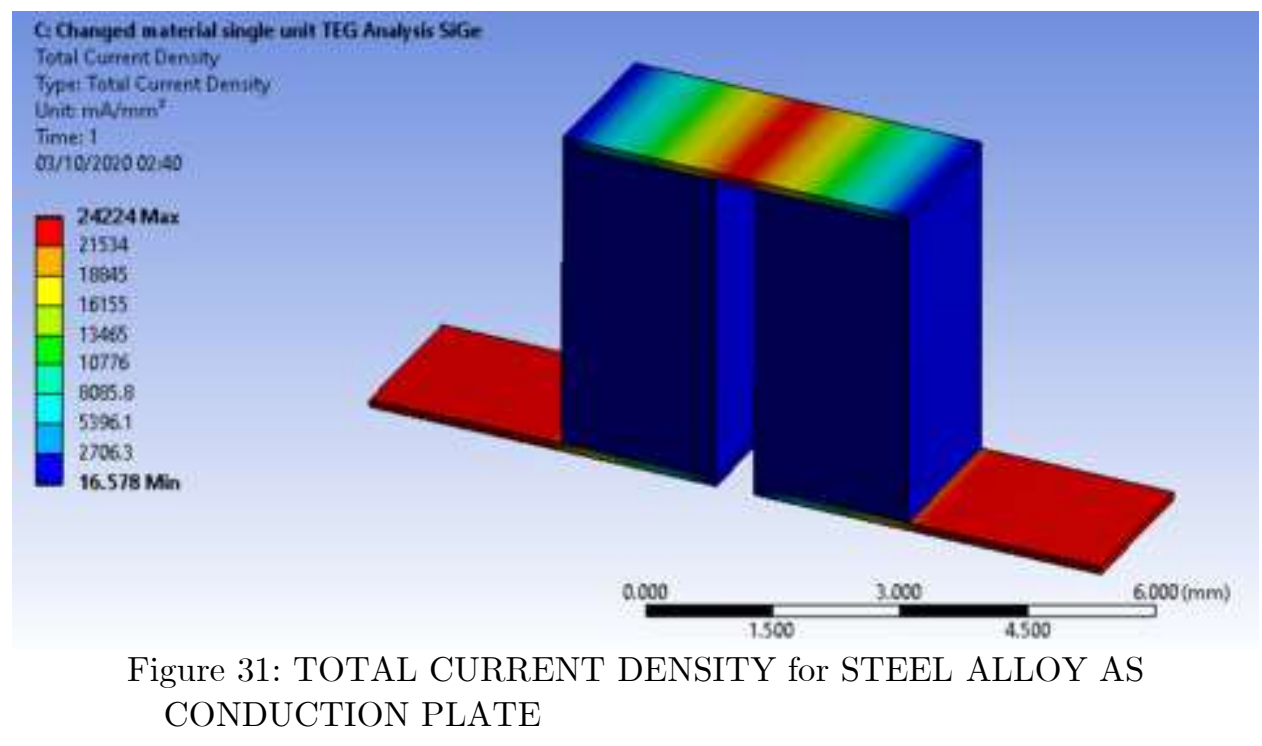

\section{Discussion}

The most important results to be discussed here are the potential difference and the current density. For this purpose, after performing the analysis on two different types of materials of conduction plate, it was noted that conduction plate does have an impact on the power output and the potential difference. Changing the material of the conduction plate from copper to steel increased the potential difference by almost twice. All the maximum values of the steel case were reduced for the given results. The maximum value of potential was higher for steel and that was the only exception.

\section{Future direction}

Right now these generators are far from perfect but they have the potential to grow into something that can be seen everywhere. The thermoelectric can be made from new polymers that are more efficient and more inexpensive. Better optimized design and low cost of production is the next step in thermoelectric power generation.

\section{Conclusion}

To comply with the need for clean and renewable energy, one of many new technologies is thermoelectric generator, working on the Seebeck principle it provides us with a different dimension. A single module of the thermoelectric generator was designed using $\mathrm{p}$ and n-type material along with conductive material and some ceramic substance. Then, the entire assembly was made and this assembly was exported to Ansys where custom materials were added and applied to the geometry. After performing analysis on the full model, a comparative study was presented in which the effect of the material of conductive plate on the voltage difference will be studied. As we know from basic principles 
the greater the potential difference $(\mathrm{V})$, the greater will be the power. So, after performing the analysis on two different types of materials of conduction plate, it was noted that this plate does affect the power output and the potential difference. Changing the material of the conduction plate from copper to steel increased the potential difference by almost twice. The results of the full model were also presented, in this case, the insulation plate was used and a very large amount of heat was absorbed by the insulation plate. The major drawback of this was that not much of the heat could reach the metallic surface as a result the temperature difference was reduced and the potential difference was also reduced. The potential was maximum in the regions where the $\mathrm{n}$ and $\mathrm{p}$-type legs were directly in front of each other. The contours of heat flux, as well as the charge density, were given. The vectors were also used to display the current density and heat flux. The heat flux arrows were from top to bottom indicating the direction of heat flow and the arrows of the current density showed the conventional direction of the current. From the above results, it can be concluded that the material of the conductive plate being used does have an impact on the power output.

\section{References}

Champier, D. (2017). Thermoelectric generators: A review of applications. Energy Conversion and Management, 140, 167-181. doi: https://doi.org/10.1016/j.enconman.2017.02.070

Ds, P., Mahajan, I., Anbalagan, R., \& Mallik, R. (2014). Design and Development of Thermoelectric Generator. AIP Conference Proceedings, 1591. doi: 10.1063/1.4872698

He, W., Zhang, G., Zhang, X., Ji, J., Li, G., \& Zhao, X. (2015). Recent development and application of thermoelectric generator and cooler. Applied Energy, 143, 1-25. doi: https://doi.org/10.1016/j.apenergy.2014.12.075

Jaziri, N., Boughamoura, A., Müller, J., Mezghani, B., Tounsi, F., \& Ismail, M. (2019). A comprehensive review of Thermoelectric Generators: Technologies and common applications. Energy Reports. doi: https://doi.org/10.1016/j.egyr.2019.12.011

Jihui Yang; Stabler, F. R. (2009). Automotive Applications of Thermoelectric Materials. Journal of Electronic Materials, 38(7), 6.

Joshi, S. (2013). Overview of Thermoelectric Power Generation Technologies- Various opportunities with Solar'.

Kim, H. S., Liu, W., Chen, G., Chu, C.-W., \& Ren, Z. (2015). Relationship between thermoelectric figure of merit and energy conversion efficiency. Proceedings of the National Academy of Sciences of the United States of America, 112(27), 8205-8210.

Kraemer, D., Poudel, B., Feng, H.-P., Caylor, J. C., Yu, B., Yan, X., . . Chen, G. (2011). Highperformance flat-panel solar thermoelectric generators with high thermal concentration. Nature Materials, 10(7), 532-538. doi: 10.1038/nmat3013

Lauck, F., Uyehara, O. A., \& Myers, P. S. (1963). An Engineering Evaluation of Energy Conversion Devices. SAE Transactions, 71, 41-50.

Mahan, G. D., \& Sofo, J. O. (1996). The Best Thermoelectric. Proceedings of the National Academy of Sciences of the United States of America, 93(15), 7436-7439.

Matsumoto, M., Mori, M., Haraguchi, T., Ohtani, M., Kubo, T., Matsumoto, K., \& Matsuda, H. (2015). Development of State of the Art Compact and Lightweight Thermoelectric Generator Using Vacuum Space Structure. SAE International Journal of Engines, 8(4), 1815-1825.

Mireles, V., \& Stultz, J. W. (1994). Radioisotope Thermoelectric Generator Waste Heat System for the Cassini Propulsion Module. SAE Transactions, 103, 548-556.

Olsten, J. A., \& Mohagheghi, S. (2017, 19-22 Oct. 2017). A low-power thermoelectric generator for off-grid power in the aftermath of natural disasters. Paper presented at the 2017 IEEE Global Humanitarian Technology Conference (GHTC).

Rohit, G., Manaswini, D., Kotebavi, V., \& S R, N. (2017). Performance study of thermo-electric generator (Vol. 1859).

Rowe, D. M. (1991). Applications of nuclear-powered thermoelectric generators in space. Applied Energy, 40(4), 241-271. doi: https://doi.org/10.1016/0306-2619(91)90020-X 
Shakouri, A. L. I., Norton, B., \& McNally, H. (2014). Solar Power and the Enabling Role of Nanotechnology. In E. D. Coyle \& R. A. Simmons (Eds.), Understanding the Global Energy Crisis (pp. 125-150): Purdue University Press.

Tang, Z. B., Deng, Y. D., Su, C. Q., Shuai, W. W., \& Xie, C. J. (2015). A research on thermoelectric generator's electrical performance under temperature mismatch conditions for automotive waste heat recovery system. Case Studies in Thermal Engineering, 5, 143-150. doi: https://doi.org/10.1016/j.csite.2015.03.006 